\title{
NOVEDADES EDITORIALES
}

Mélanie Albaret, Le Brésil et le Mexique aux Nations unies: puissances émergentes dans le jeu international, París, Presses de Sciences Po, 2014, 200 pp.

Brasil y México han cambiado sus estrategias de presencia internacional desde la creación de la onu en 1945 a la fecha. La autora sigue la trayectoria de ambos países; sostiene que ambos han pasado de una postura pasiva en los primeros años a una actitud más activa de cooperación multilateral. Albaret estudia de esta forma los mecanismos de posicionamiento internacional de dos potencias medias.

Pierre Blanc y Jean-Paul Chagnollaud, Violence et politique au MoyenOrient, París, Presses de Sciences Po, 2014, 256 pp.

Los autores proponen cinco dimensiones para explicar los conflictos en Medio Oriente: territorio, ideología, identidad, régimen y derecho internacional. En todos estos aspectos, los autores perciben un abandono de la política como mecanismo de diálogo y creación de compromisos.

Charles W. Calomiris y Stephen H. Haber, Fragile by Design: The Political Origins of Banking Crises and Scarce Credit, Princeton, Princeton University Press, 2014, 584 pp.

Este libro analiza la trayectoria histórica y política de los sistemas bancarios en Canadá, Estados Unidos, México y Brasil. Según los autores, las coaliciones entre políticos, banqueros y otros grupos de poder fueron decisivas para diseñar dichas 
instituciones, y explican la existencia y utilidad de las regulaciones bancarias en la actualidad.

Cathryn Costello y Mark Freedland (eds.), Migrants at Work: Immigration and Vulnerability in Labour Law, Nueva York, Oxford University Press, 2014, 512 pp.

Los autores examinan la intersección entre legislación laboral y leyes migratorias. La migración y las leyes que la regulan afectan los derechos laborales, generan estatus de empleo particulares y cambian los enfoques de protección de los trabajadores. Los capítulos presentan las trayectorias y la interacción entre estos ámbitos jurídicos en Reino Unido, Australia, Irlanda, Estados Unidos, Israel y la Unión Europea, entre otros.

Deborah James, Money from Nothing: Indebtedness and Aspiration in South Africa, Stanford, Stanford University Press, 2014, 304 pp.

Deborah James estudia en este libro un proyecto de inclusión financiera en Sudáfrica, cuyo objetivo es extender la oferta de créditos. Frente a la popularidad de programas de microcréditos en los países en desarrollo, James contrapone un estudio sobre los determinantes de obtención de crédito para las clases media y trabajadora y las posibilidades de que estos esquemas generen nuevos modos de opresión y dependencia.

Monika Krause, The Good Project: Humanitarian Relief NGOs and the Fragmentation of Reason, Chicago, Chicago University Press, 2014, 240 pp.

La autora de este libro analiza los procesos de toma de decisiones de las ONG de ayuda humanitaria; arguye que estas instituciones se esfuerzan en producir y vender proyectos a donantes. En el proceso, los beneficiarios pasan a un segundo plano, y el tipo de proyectos que compiten por ayuda internacional no siempre responde a las necesidades más apremiantes de la población beneficiaria. 
Odette Lienau, Rethinking Sovereign Debt: Politics, Reputation, and Legitimacy in Modern Finance, Cambridge, Harvard University Press, 2014, 344 pp.

La continuidad de la deuda soberana en casos de cambio de régimen se convirtió en consenso internacional desde la Primera Guerra Mundial. El supuesto que empuja a los nuevos regímenes a pagar deuda contratada por sus antecesores reside en conceptos como legitimidad y reputación, auspiciados por organismos internacionales. Una cancelación selectiva de la deuda ha sido factible históricamente, y debe anteponerse un análisis político y de precedentes históricos a una búsqueda de reputación.

Grégoire Mallard, Fallout: Nuclear Diplomacy in an Age of Global Fracture, Chicago, University of Chicago Press, 2014, 384 pp.

Grégoire Mallard examina el Tratado de No Proliferación Nuclear de 1968. Compara el seguimiento del Tratado en Europa con los casos de la India, Israel y Pakistán. El autor se enfoca en la opacidad de las reglas y las dificultades de interpretación como un obstáculo para que estos tres países se adhieran a este vital tratado internacional.

Terje Rod-Larsen, Nur Laiq y Fabrice Aidan, The Search for Peace in the Arab-Israeli Conflict: A Compendium of Documents and Analysis, Nueva York, Oxford University Press, 2014, 1346 pp.

Este libro, coordinado por el International Peace Institute, reúne documentos sobre el conflicto árabe-israelí de 1916 a la fecha. El compendio incluye mapas, tratados formales e informales y documentos oficiales comentados y anotados por los autores. La riqueza de fuentes y referencias que provee permite comprender a detalle la evolución del conflicto y sus intentos de resolución. 
Melanie Jean Springer, How the States Shaped the Nation: American Electoral Institutions and Voter Turnout, 1920-2000, Chicago, University of Chicago Press, 2014, 240 pp.

Estados Unidos tiene una de las menores tasas de participación electoral de los países desarrollados; esto se debe a las importantes diferencias entre instituciones electorales locales. El proceso histórico y político de dichas instituciones debe ser analizado para entender el desapego ciudadano con las elecciones a nivel nacional.

E. Sridharan (ed.), International Relations Theory and South Asia Security, Political Economy, Domestic Politics, Identities, and Images, Nueva Delhi, Oxford University Press India, 2014, dos volúmenes.

Los autores utilizan la teoría de relaciones internacionales para conceptualizar los conflictos más apremiantes del sur de Asia, las relaciones bilaterales entre la India y Pakistán, la búsqueda de un modelo compartido de seguridad o el difícil ajuste de Sri Lanka después de la guerra civil. Además de exhaustivos estudios de caso, estos dos volúmenes presentan diversas perspectivas disciplinarias para el estudio de las relaciones internacionales, como modelos de cooperación regional y procesos de identidad compartida, entre otros.

Charles Tilly, Credit and Blame, Princeton, Princeton University Press, 2014, 198 pp.

Tilly expone en este libro póstumo distintas aproximaciones a un mismo tema: la forma en que el ser humano asigna culpas y otorga elogios. El reconocido sociólogo recurre a ejemplos tan variados como comisiones de la verdad o conversaciones de pasillo para esclarecer un proceso intrínseco a las relaciones sociales, y vital para la producción de una idea compartida de justicia.

Colaboración de María Fernanda López Portillo Alcocer 